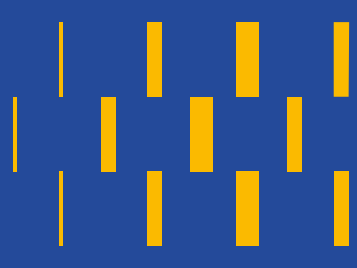

\title{
Horticultura, movilidad y tecnología lítica: una mirada desde Boyo Paso 2 (900-700 años AP, Sierras de Córdoba, Argentina)
}

\section{Horticulture, mobility and lithic technology: a view from Boyo Paso 2 (900-700 years BP, Sierras of Córdoba, Argentina)}

\author{
Imanol Balena ${ }^{1,2}$ (D) https://orcid.org/0000-0001-6276-1153 \\ Matías E. Medina1,2 (iD) https://orcid.org/0000-0003-1768-5811 \\ ${ }^{1}$ Consejo Nacional de Investigaciones Científicas y Técnicas, ARGENTINA \\ ${ }^{2}$ División Arqueología, Facultad de Ciencias Naturales y Museo, Universidad Nacional de La Plata, Av. 122 \\ y 60 (1900), La Plata, Buenos Aires, ARGENTINA. \\ Email: paleomedina@gmail.comimanol.balena@gmail.com
}

\section{Resumen}

En este artículo se analizan los núcleos, desechos y artefactos líticos recuperados en el sitio arqueológico Boyo Paso 2 (Sierras de Córdoba, Argentina), un asentamiento a cielo abierto interpretado como un campamento base ocupado durante la estación productiva (octubre-abril) por grupos que combinaban cultivos, caza-recolección y patrones de uso flexible del espacio. El objetivo principal es presentar los resultados y contribuir a la caracterización de la organización de la tecnología lítica durante el Período Prehispánico Tardío (1500-360 AP), cuya información sugiere que la incorporación de cultivos no restringió la movilidad estacional ni el tiempo invertido en la caza-recolección. Los datos apuntaron hacia la existencia de un cierto componente tecnológico conservado entre los grupos tardíos, que, junto con la expeditividad, regía la organización de la tecnología. El aprovechamiento intensivo de aquellas rocas de mejor calidad para la talla y menos abundantes en el paisaje, en un contexto dominado por estrategias tecnológicas expeditivas, da particular relevancia a los resultados obtenidos, en especial para comprender la amplitud de respuestas tecnológicas en casos en los que la adopción de cultivos no necesariamente derivó en una agricultura sedentaria, un patrón observado etnográficamente pero difícil de delimitar desde la cultura material.

Palabras clave: organización de la tecnología, economías mixtas, cultivo, caza-recolección, uso flexible del espacio. 


\begin{abstract}
This article analyzes the core technology, flaked stone artifacts manufacture debris and tools recovered at Boyo Paso 2 (Sierras de Córdoba, Argentina), an open-air site interpreted as a residential base-camp occupied during the growing season (October-April) by people with mixed foraging and cultivation economy. The major aim is to present the results and characterize the organization of lithic technology during the Late Pre-Hispanic Period (1500-360 BP), where the adoption of plant cultivation did not constrained the group's mobility or the time investment into other subsistence activities as foraging. Results pointed out the existence of certain curated technological component among late prehispanic groups, which in conjunction with expedient flake-tool production strategies governed the organization of technology. The intensive exploitation of fine-grain lithic but less abundant in the landscape raw materials, in a context dominated by expedient tools, provides primary data to understand the variability of technological responses where the adoption of crop plants did not necessarily lead to fullysedentary farming, a pattern commonly observed ethnographically but difficult to identify from the material culture.
\end{abstract}

Keywords: lithic organization, mixed economies, farming, foraging, flexible landscape-use.

Recibido: 14 agosto 2020. Aceptado: 23 noviembre 2020 


\section{Introducción}

El estudio arqueológico del Período Prehispánico Tardío de las Sierras de Córdoba (1500-360 AP, Argentina) durante décadas asumió que la incorporación de cultivos rápidamente derivó en una mayor dependencia en las plantas domesticadas y en la sedentarización de los grupos en poblados permanentes similares a los observados en otras partes del mundo a lo largo de la transición hacia la producción de alimentos (Aparicio, 1939; González, 1943; Serrano, 1945; Berberián, 1984; Laguens y Bonnín, 2009). Sin embargo, la información actualmente disponible impide sostener que el cultivo haya sido la estrategia económica de mayor jerarquía como para justificar un sedentarismo estricto, reformulando la visión tradicional sobre el cambio cultural (Medina et al., 2014, 2016, 2018, 2019a, 2019b, 2020). En contraposición, los datos sugieren que las sociedades tardías desarrollaron una economía mixta que combinaba cultivos a pequeña escala con aportes significativos de caza-recolección, en los que la flexibilidad fue uno de los rasgos definitorios (Medina et al., 2014). La cerámica, el maíz (Zea mays) y otros cultígenos fueron extensivamente utilizados, pero en el marco de una estrategia de subsistencia diversificada que incluía un alto grado de movilidad a lo largo del ciclo anual (Pastor et al., 2012; Medina et al., 2016, 2018). De este modo, la caza-recolección continuó cubriendo una parte importante de la dieta, mientras que la agricultura fue estacionalmente interrumpida cuando los recursos silvestres de mayor rendimiento se encontraban disponibles en otros puntos del paisaje. En consecuencia, los grupos tardíos hicieron un uso estacional y diversificado del paisaje, y las unidades domésticas o familiares constituyeron pequeños núcleos relativamente autónomos de producción, consumo y de ocupación del espacio, que se agregaban o dispersaban ajustándose a las cambiantes circunstancias del entorno (Pastor et al., 2012; Medina et al., 2014, 2016).

Avanzar en el conocimiento de poblaciones que combinaron caza-recolección, cultivos y poblados semisedentarios implica el desafío de comprender e identificar las distintas formas y niveles que alcanzaron, incluso en el largo plazo, evitando clasificar los datos en categorías artificiales de poco poder explicativo (Smith, 2001; Asouti y Fairbain, 2010). En los últimos años las investigaciones sobre restos botánicos y faunísticos se presentaron como un foco obvio de análisis para argumentar posibles alternancias estacionales, oscilaciones y reversiones entre las prácticas de subsistencia y movilidad (Medina et al., 2011, 2019b, 2020; Recalde y López, 2017; López, 2018). Sin embargo, la falta de preservación de materiales orgánicos resultó ser un factor limitante (Medina et al., 2020). Una alternativa viable para lograr avances significativos es enfocarse en esclarecer cómo los grupos tardíos trataron con un conjunto compartido de problemas y soluciones utilizando uno de los elementos mejor representados en el registro arqueológico, a saber, los conjuntos líticos (Holdaway et al., 2010). En este sentido, si las características de los artefactos, núcleos y desechos líticos pueden relacionarse con el grado de movilidad o de dependencia sobre los cultivos, los resultados permitirían abrir una forma productiva de comparación intercultural entre cazadores-recolectores y agricultores, contribuyendo a ampliar y/o reformular los modelos vigentes sobre cómo los humanos ajustaron sus estrategias tecnológicas durante la transición hacia la producción de alimentos (Parry y Kelly, 1987; Torrence, 1994; Andrefsky, 1998; Chaparro, 2001; Escola, 2004; Hocsman, 2014; Lucero et al., 2016).

A los efectos de superar el vacío de información, en este artículo se propone abordar el análisis tecnomorfológico de los núcleos y desechos de talla recuperados en Boyo Paso 2 (900-700 AP, Sierras de Córdoba), un sitio a cielo abierto interpretado como un campamento base ocupado 
durante la estación productiva (octubre-abril) por grupos que combinaban cultivos, caza-recolección y patrones de uso flexible del espacio (Figura 1). La información sobre los artefactos líticos tallados ha sido en gran parte publicada y solo será contemplada en forma secundaria (Medina et al., 2019a, 2019c; Balena, 2020; Medina y Balena, 2021). El estudio parte del supuesto de que los núcleos y desechos de talla aportan datos claves sobre las estrategias de producción lítica llevadas a cabo en el lugar de descarte (Holdaway et al., 2010), proveyendo información relevante sobre el abastecimiento de rocas y el proceso de reducción y producción de formas base (Andrefsky, 1998; Clarkson, 2008). El objetivo principal, entonces, es presentar los resultados y contribuir a la caracterización de la organización de la tecnología lítica durante el Período Prehispánico Tardío, en el marco de un nicho económico diversificado con alta movilidad estacional. El análisis se focalizó en medir la inversión del trabajo o energía involucrada en el proceso de producción de artefactos y sus relaciones con las materias primas, asumiendo un uso diferencial de las mismas en función de su disponibilidad en el paisaje y propiedades para la talla. En este sentido, el propósito es ampliar el conocimiento sobre las estrategias tecnológicas adoptadas en contextos donde la incorporación de cultivos no restringió la movilidad estacional del grupo ni el tiempo invertido en la caza-recolección, un tema escasamente contemplado en los estudios líticos por su baja visibilidad arqueológica y ausencia de marcos interpretativos adecuados. En otras palabras, lo que se busca es generar antecedentes teórico-metodológicos que permitan caracterizar la toma de decisiones tecnológicas durante la transición de la caza-recolección hacia economías productivas, y que sean útiles para interpretar casos arqueológicos en los que el abandono contingente de las estrategias productivas pudo haber sido más frecuente que lo tradicionalmente esperado.

\section{El sitio}

Boyo Paso 2 (3119'3.96” S, 6459'43.16” O, $1160 \mathrm{msnm}$ ) es un sitio a cielo abierto localizado en el sector oriental del valle de Salsacate, Provincia de Córdoba (Argentina, Figura 1). El entorno inmediato es de Chaco Serrano (Giorgis et al., 2011), con amplias posibilidades para la recolección de frutos silvestres y suelos potencialmente cultivables restringidos por lomadas rocosas, en cuyas laderas abundan cuarzos y andesitas de regular calidad para la talla (Arnosio et al., 2014; Medina et al., 2020).

Las excavaciones realizadas hasta el momento revelaron dos pisos arqueológicos de ocupación asociados a una gran diversidad de restos arqueológicos, incluyendo restos faunísticos, estatuillas antropomorfas y los materiales líticos en parte aquí analizados. El remontaje de los fragmentos cerámicos permitió interpretar que los pisos promedian una serie de eventos cercanos en el tiempo, consistentes con ocupaciones de tipo estacional (Medina et al., 2020). Por otra parte, los pisos no tienen indicadores que marquen ocupaciones de grupos con distinto tipo de subsistencia, tecnología u organización social, siendo el rango temporal señalado por las dataciones radiocarbónicas discutidas más abajo lo esperable para un "componente" resultado de ocupaciones similares próximas en el tiempo, motivo por el cual los materiales son presentados $\mathrm{y}$ analizados en forma conjunta sin diferenciar por pisos.

La diversidad taxonómica y el tamańo de los conjuntos faunísticos, junto con la alta densidad de restos cerámicos y líticos recuperados en estratigrafía, son indicativos de estadías de varios meses en el sitio, un argumento reforzado por la detección de residuos de la elaboración de recipientes cerámicos, una actividad que requiere algunas semanas o meses de estabilidad residencial para completar el ciclo de producción (Medina et al., 2019a, 2019b, 2019c, 2020). 


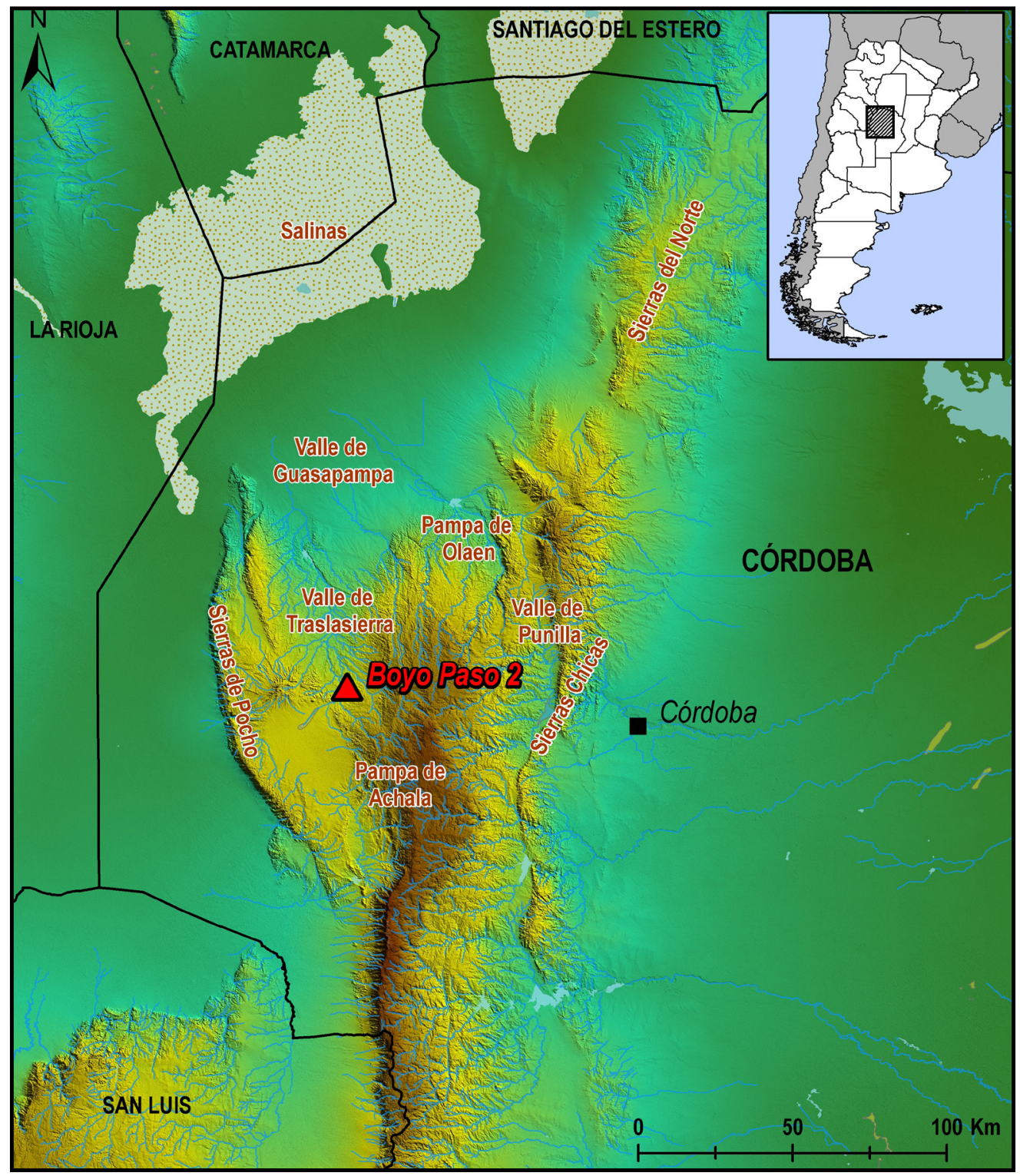

Figura 1. Ubicación geográfica del sitio arqueológico Boyo Paso 2.

La explotación de plantas y animales está claramente documentada en los conjuntos artefactuales, que incluyen puntas de proyectil, instrumentos de molienda, vasijas e instrumentos con filos agudos y/o aserrados como para despostar o procesar carcasas, semillas, tubérculos y/o elaborar artefactos involucrados en el procesamiento de los subproductos de una economía de amplio espectro (Medina et al., 2018, 2019a, 2019c). Los indicadores faunísticos de estacionalidad (es decir, huevos de Rheidae, huesos de Salvator sp. y osteodermos de Euphractinae), junto con evidencias de actividades agrícolas (macrorrestos de Zea mays, Phaseolus spp., etc.) y de recolección (Oxalis sp.; Sarcomphalus mistol, Geoffroea decorticans, Prosopis sp., etc.), apoyan la hipótesis de que la ocupación de Boyo Paso 2 coincidió con la primavera-verano, momento del año en que debía realizarse la siembra, cosecha y/o que los recursos silvestres estaban disponibles en los alrededores del sitio (Medina et al., 2020). La existencia de estructuras habitacionales se infirió a 
partir de la presencia de numerosos agujeros de postes (Medina et al., 2016). La disposición azarosa de los mismos y la ausencia de fogones formales impidieron determinar la forma, número y tamaño de las estructuras, reforzando la hipótesis de una arquitectura de características efímeras y no planificada para un uso a largo plazo (sensu Diehl, 1997). Siete fechados radiocarbónicos fueron obtenidos en el sitio (Tabla 1). Sin embargo, dos fechas del piso superior $-1060 \pm 50 \mathrm{y}$ $1500 \pm 80$ años $\mathrm{AP}$ - son estadísticamente más antiguas que aquellas obtenidas en el piso inferior y fueron excluidas del análisis (Medina et al., 2020). Los restantes fechados se superponen estadísticamente, posicionando los pisos entre 900-700 ańos AP y confirmando que se formaron en un período relativamente corto (Medina et al., 2016). Con base en las evidencias Boyo Paso 2 es interpretado como un sitio formado por ocupaciones estivales de unas pocas familias para realizar actividades diversas propias de los espacios residenciales en el marco de una estrategia económica mixta que combinaba cultivos, caza-recolección junto con un uso estacional y diversificado del paisaje, ofreciendo una excelente oportunidad para analizar la organización de la tecnología lítica durante el Período Prehispánico Tardío, cuando tácticas, comportamientos y estrategias se repitieron en una escala temporal evolutiva.

Tabla 1. Fechados radiocarbónicos de Boyo Paso 2 (tomado de Medina et al., 2020). La calibración se hizo utilizando Calib Rev. 7.0.1 (Reimer et al., 2013).

\begin{tabular}{|l|c|c|c|c|c|}
\hline \multirow{4}{*}{$\begin{array}{l}\text { Unidad } \\
\text { estratigráfica }\end{array}$} & $\begin{array}{c}\text { Material } \\
\text { datado }\end{array}$ & ${ }^{14} \mathbf{C}$ ańos & Sigma & $\begin{array}{c}\text { Código } \\
\text { delaboratorio }\end{array}$ & Edad calibrada \\
\hline \multirow{4}{*}{$\begin{array}{l}\text { Piso superior } \\
(37-40 \mathrm{~cm})\end{array}$} & $\begin{array}{c}\text { Carbón } \\
\text { vulgareolus }\end{array}$ & 750 & 70 & LP-2932 & $549-744$ AP \\
\cline { 2 - 6 } & Zea mays & 866 & 39 & AA110929 & $658-908$ AP \\
\cline { 2 - 6 } & Carbón & 1060 & 50 & AA110928 & $716-774$ AP \\
\cline { 2 - 6 } & Carbón & 1500 & 80 & LP-3107 & $1261-1538$ AP \\
\hline \multirow{2}{*}{$\begin{array}{l}\text { Piso inferior } \\
(49-56 \mathrm{~cm})\end{array}$} & Carbón & 870 & 50 & LP-3577 & $666-808$ AP \\
\cline { 2 - 6 } & Carbón & 970 & 40 & LP-3567 & $757-924$ AP \\
\hline
\end{tabular}

\section{Materiales y métodos}

La muestra está constituida por 40 núcleos y 1034 desechos de talla, entre lascas enteras y lascas fragmentadas con talón. Por otro lado, el número de artefactos formatizados asciende a 112 (ver Medina et al., 2019a, 2019c; Balena, 2020; Medina y Balena 2021).

Las materias primas se determinaron de forma macroscópica y a partir de cortes delgados. Los datos referentes a su distribución, disponibilidad y calidad provienen de la literatura arqueológica (Argüello de Dorsch, 1983; Heider et al., 2015; Heider et al., 2020) y geológica (Petersen y Lanza, 1979; Arnosio et al., 2014). De este modo, el cuarzo, una roca de regular calidad 
para la talla, pero con una distribución prácticamente continua en las Sierras de Córdoba, fue considerado una roca inmediatamente disponible a escasos metros del sitio (Heider et al., 2015). Una situación similar ocurre con la andesita, una roca abundante a pocos cientos de metros del sitio, pero restringida al paisaje volcánico donde se localiza Boyo Paso 2 (Arnosio et al., 2014). La calcedonia, de grano fino y mejor calidad para la talla de artefactos, también está disponible dentro del rango de aprovisionamiento del sitio $(<10 \mathrm{~km})$. Sin embargo, al encontrarse en forma de pequeñas venas de difícil detección sus costos de obtención son más altos que el cuarzo y la andesita (Argüello de Dorsch, 1983; Arnosio et al., 2014). Además, las características visualmente heterogéneas de la calcedonia recuperada en estratigrafía sugieren que probablemente fueron obtenidas de múltiples fuentes, algunas de ellas fuera del rango de aprovisionamiento del sitio, como por ejemplo, en la Formación Mina Clavero, ca. 60 km, o en la Sierra de La Estanzuela, a más de 150 km (Argüello de Dorsch, 1983; Sario, 2013; Sario et al., 2017; Heider et al., 2020). El ópalo, por otra parte, proviene de fuentes localizadas a $100 \mathrm{~km}$ al norte del sitio (Argüello de Dorsch, 1983; Heider et al., 2015), por lo que se define como una roca no local, cuyo aprovisionamiento requería de mecanismos sociales más complejos y costosos, que involucraban movilidad y/o intercambio con grupos de áreas más alejadas.

En los núcleos se consideró la forma, porcentaje de corteza, tipo de núcleo, dimensiones, cantidad y tipo de extracciones, mientras que en los desechos de talla se analizó el tipo de lasca, dimensiones ${ }^{1}$ y tipo de talón (Aschero, 1983; Andrefsky, 1998; Symons, 2003; Paulides, 2006). Tanto en los núcleos como en los desechos de talla se asumió que el porcentaje de corteza y el tamaño de la pieza disminuyen a medida que el proceso de reducción avanza y/o más intensiva es la explotación de la materia prima, siendo la base para establecer si los productos de la reducción del núcleo están presentes en el conjunto, fueron removidos del sitio o bien fueron importados desde otras locaciones (Dibble et al., 2005; Clarkson, 2008; Holdaway et al., 2010). Estos aspectos fueron evaluados a partir de una serie de medidas e índices propuestos por Dibble et al. (2005), Symons (2003) y Cardillo et al. (2017), como la proporción de núcleos con y sin corteza, la razón lascas:núcleos, y el rango entre lascas corticales y no corticales. En los núcleos también se contabilizó el número de extracciones, que tiende a ser mayor a medida que aumenta la reducción, proceso que también deriva en que los núcleos se hagan más pequeños. En cuanto a las lascas, se espera que el tamaño decrezca a medida que se avanza en la secuencia de reducción (Symons, 2003; Cardillo et al., 2017). Los talones fueron utilizados para evaluar la etapa de la secuencia de reducción, considerando que altas frecuencias de talones naturales y lisos son indicativos de las primeras etapas de producción, mientras que los facetados sugieren plataformas previamente preparadas y que los talones de tipo filiformespuntiformes se relacionan con la talla por presión para el mantenimiento de los filos (Symons, 2003). Finalmente, el análisis de los artefactos, en parte ya publicado, siguió los lineamientos de Aschero (1983) y Aschero y Hocsman (2004).

\section{Resultados}

En líneas generales, los núcleos de Boyo Paso 2 se correspondieron con núcleos de lascas, predominando las formas denominadas de lascados aislados (sensu Aschero, 1983), en donde no hay una búsqueda de una forma de lasca en particular (Tabla 2 y Tabla 3). En el cuarzo y la andesita, materias primas locales sobre las cuales se elaboraron la mayor cantidad de núcleos, se observó cierta variabilidad en cuanto a los tamaños y morfologías, predominando aquellos núcleos de tamaño Grande, Mediano-grande y las formas de lascados aislados (ver Tabla 2 y

1 Las variables dimensionales se expresaron en milímetros y solo se consideraron piezas enteras $(\mathrm{N}=627)$. 
Tabla 3; Figura 2a-d). A pesar de que la razón mayor entre lascas y núcleos se da en estas rocas, casi todos los núcleos se descartaron con reserva de corteza, indicando baja intensidad de reducción y que no estarían agotados, un aspecto claramente visible en los altos valores de la relación núcleos con y sin corteza (Tabla 3 y Tabla 4). En los núcleos de calcedonia y ópalo, rocas silíceas de mejor calidad para la talla, predominaron las formas bipolares y de tamaño Pequeño (Figura 2e-f), evidenciando reservas de corteza nulas o menores al 25\%, mayor intensidad de reducción e importantes signos de agotamiento (Tabla 3, Tabla 4 y Tabla 5). La totalidad de los núcleos recuperados en Boyo Paso 2, independientemente de la materia prima, señalaron cantidades similares de extracciones (Tabla 5), aunque se observó un número mayor de negativos de lascado y una mayor dispersión de valores en los núcleos de calcedonia y ópalo, aunque este último representado por un solo ejemplar.

Tabla 2. Características generales del conjunto lítico de Boyo Paso 2.

\begin{tabular}{|c|c|c|c|c|c|c|}
\hline \multirow{2}{*}{ Clase técnica } & \multicolumn{5}{|c|}{ Materia prima } & \multirow{2}{*}{ Total } \\
\hline & Cuarzo & Andesita & Calcedonia & Ópalo & Indeterminada & \\
\hline Núcleos & 15 & 11 & 10 & 1 & 3 & 40 \\
\hline Desechos & 324 & 344 & 284 & 35 & 47 & 1034 \\
\hline FNCRC & 1 & 8 & 2 & - & - & 11 \\
\hline $\begin{array}{l}\text { Artefactos } \\
\text { formatizados }\end{array}$ & $\begin{array}{l}\text { Raederas: } 1 \\
\text { Raspador: } 2 \\
\text { Afs: } 7 \\
\text { perforador: } 5 \\
\text { Muesca: } 3 \\
\text { Punta no } \\
\text { destacada: } 1 \\
\text { Percutor: } 1 \\
\text { Puntas de } \\
\text { proyectil: } 3\end{array}$ & $\begin{array}{l}\text { Raspador: } 1 \\
\text { Afs: } 17 \\
\text { cuchillo: } 1 \\
\text { Percutor: } 1\end{array}$ & $\begin{array}{l}\text { Raederas: } 5 \\
\text { Raspador: } 3 \\
\text { Afs: } 11 \\
\text { perforador: } 3 \\
\text { cuchillo: } 1 \\
\text { Puntas de } \\
\text { proyectil: } 34\end{array}$ & $\begin{array}{l}\text { Raspador: } 1 \\
\text { Puntas de } \\
\text { proyectil: } 4\end{array}$ & $\begin{array}{l}\text { Afs: } 3 \\
\text { Puntas de } \\
\text { proyectil: } 4\end{array}$ & 112 \\
\hline
\end{tabular}

Nota: FNCRC: Filos naturales con rastros complementarios. Afs: Artefacto de formatización sumaria. 


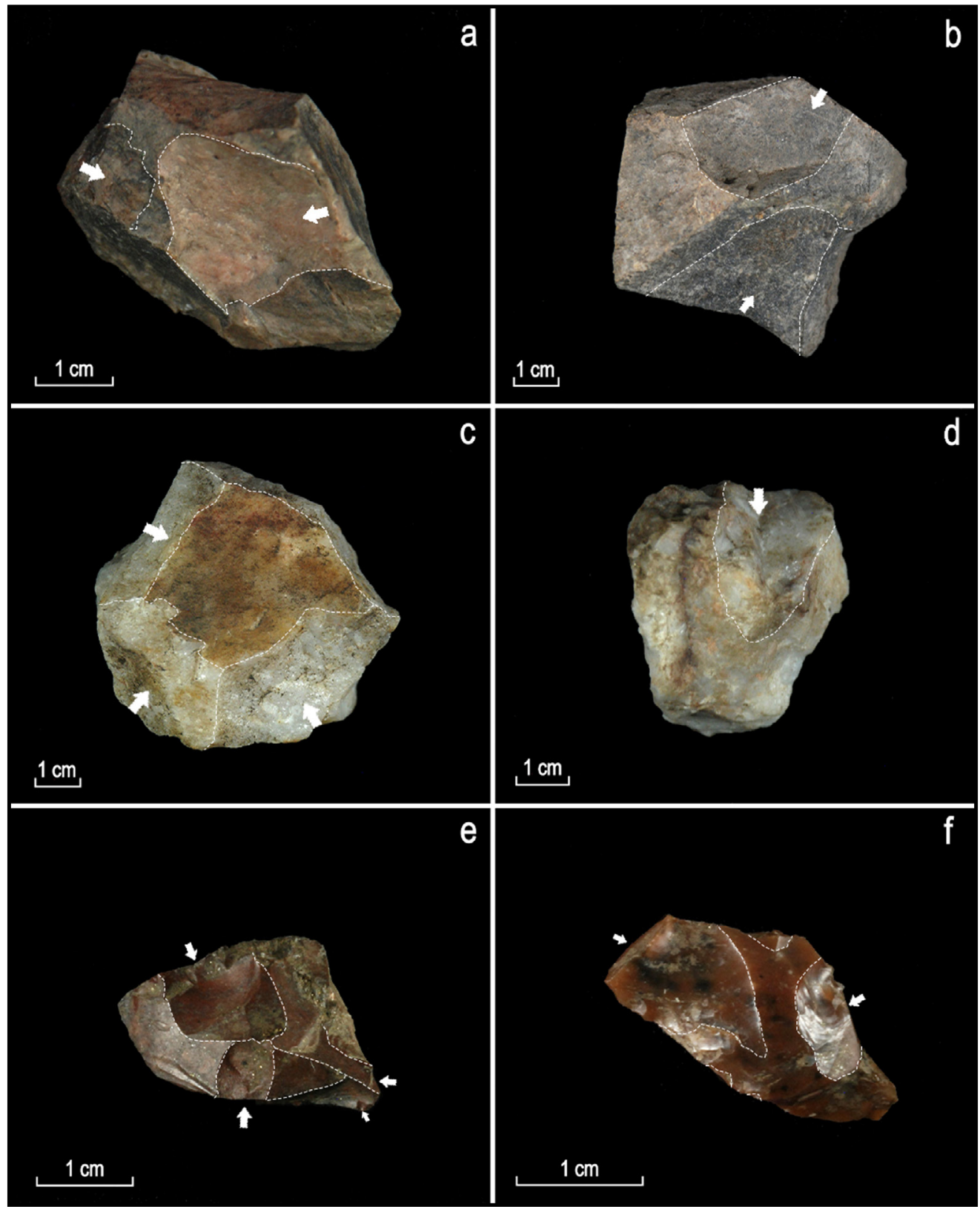

Figura 2. Algunos núcleos de Boyo Paso 2. a) núcleo de andesita con lascados aislados; b) núcleo discoidal irregular de andesita; c) núcleo poliédrico de cuarzo; d) núcleo de cuarzo con lascados aislados; e) Núcleo calcedonia con evidencias de talla bipolar; f) Núcleo calcedonia con evidencias de talla bipolar. 
Tabla 3. Frecuencias y características generales de los núcleos recuperados en Boyo Paso 2 discriminados por materia prima.

\begin{tabular}{|c|c|c|c|c|c|}
\hline $\begin{array}{l}\text { Materia } \\
\text { prima }\end{array}$ & $\mathbf{N}$ & Agotamiento & Forma & Tamaño & $\begin{array}{r}\text { Presencia } \\
\text { de corteza }\end{array}$ \\
\hline Cuarzo & 15 & $\begin{array}{c}\text {-Agotados: } 2 \\
\text {-No agotados: } 13\end{array}$ & $\begin{array}{c}\text {-Poliédrico: } 1 \\
\text {-Lascados aislados: } 8 \\
\text {-Bipolares: } 2 \\
\text {-No diferenciado: } 4\end{array}$ & $\begin{array}{c}\text {-Pequeńo: } 3 \\
\text {-Mediano-pequeño: } 2 \\
\text {-Mediano-grande: } 5 \\
\text {-Grande: } 5\end{array}$ & $\begin{array}{c}-0 \%: 2 \\
-1-25 \%: 2 \\
-26-50 \%: 4 \\
-21-75 \%: 4 \\
->75 \%: 3\end{array}$ \\
\hline Andesita & 11 & $\begin{array}{c}\text {-Agotados: } 0 \\
\text {-No agotados: } 11\end{array}$ & $\begin{array}{c}\text {-Discoidal irregular: } 1 \\
\text {-Poliédrico: } 1 \\
\text {-Bipiramidal: } 2 \\
\text {-Lascados aislados: } 7\end{array}$ & $\begin{array}{c}\text {-Mediano-pequeño : } 2 \\
\text {-Mediano-grande: } 6 \\
\text {-Grande: } 3\end{array}$ & $\begin{array}{c}-0 \%: 0 \\
-1-25 \%: 3 \\
-26-50 \%: 3 \\
-21-75 \%: 2 \\
->75 \%: 3\end{array}$ \\
\hline Calcedonia & 10 & $\begin{array}{l}\text {-Agotados: } 5 \\
\text {-No agotados: } 5\end{array}$ & $\begin{array}{c}\text {-Poliédrico: } 1 \\
\text {-Bipiramidal: } 1 \\
\text {-Globuloso: } 1 \\
\text {-Bipolar: } 4 \\
\text {-No diferenciado: } 3\end{array}$ & $\begin{array}{c}\text {-Pequeño: } 8 \\
\text {-Mediano-pequeño: } 2\end{array}$ & $\begin{array}{c}-0 \%: 6 \\
-1-25 \%: 3 \\
-26-50 \%: 1 \\
-21-75 \%: 0 \\
->75 \%: 0\end{array}$ \\
\hline Ópalo & 1 & $\begin{array}{l}\text {-Agotados: } 1 \\
\text {-No agotados: } 0\end{array}$ & -Bipolar: 1 & -Pequeño: 1 & $\begin{array}{c}-0 \%: 1 \\
-1-25 \%: 0 \\
-26-50 \%: 0 \\
-21-75 \%: 0 \\
->75 \%: 0\end{array}$ \\
\hline Indeterminadas & 3 & $\begin{array}{l}\text {-Agotados: } 0 \\
\text {-No agotados: } 3\end{array}$ & -Lascados aislados: 3 & $\begin{array}{l}\text {-Mediano-pequeño: } 1 \\
\text {-Mediano-grande: } 2\end{array}$ & $\begin{array}{c}-0 \%: 0 \\
-1-25 \%: 0 \\
-26-50 \%: 2 \\
-21-75 \%: 1 \\
->75 \%: 0\end{array}$ \\
\hline
\end{tabular}

Entre los desechos de talla predominaron los de andesita, seguidos por los de cuarzo y, en menor medida, calcedonia (Tabla 2 y Tabla 6). Las materias primas indeterminadas y el ópalo presentaron frecuencias relativamente bajas (Tabla 6). Las lascas enteras fueron mayoritarias en materias primas como la calcedonia, el ópalo y las indeterminadas, mientras que en la andesita y el cuarzo la distribución entre lascas enteras y fragmentadas fue más balanceada, con un leve predominio de las primeras (Tabla 6). Los desechos de cuarzo, andesita y calcedonia presentaron mayoritariamente tamaños Muy Pequeño y Pequeño, aunque en los dos primeros las piezas de tamaño Grande también fueron comunes (Tabla 6). En la calcedonia no se identificaron desechos de tamaño Grande. En cambio, se documentaron microlascas e hipermicrolascas, que en el ópalo fueron los tamaños más representados. Por otra parte, en la andesita y el cuarzo hubo un claro predominio de lascas internas, aunque sin registro de lascas de adelgazamiento (Tabla 4 y Tabla 6). De todas maneras, el rango bajo entre lascas sin y con corteza indica que la proporción de lascas externas fue alta en la andesita, seguida por el cuarzo, mientras que en este último también se registraron lascas de reactivación en baja frecuencia (Tabla 4 y Tabla 6). En rocas como la calcedonia, se determinó una presencia mayoritaria de lascas internas -visible en el número mayor de la razón lascas sin y con corteza- y, en menor proporción, de reactivación 
y adelgazamiento (Tabla 4 y Tabla 6). El ópalo es la otra materia prima que presentó lascas de adelgazamiento, aunque en bajas frecuencias, mientras que en las materias primas indeterminadas hubo una clara supremacía de lascas externas, aunque también se documentaron lascas internas (Tabla 4 y Tabla 6). Por último, el análisis de los talones es concordante con todo lo argumentado más arriba, sugiriendo el predominio de los talones lisos y corticales en el cuarzo y la andesita (Tabla 7), indicativos de las primeras etapas de reducción de núcleos. En la calcedonia y el ópalo la proporción se invierte, con valores elevados de talones que evidencian un estado avanzado en la reducción de los núcleos (Tabla 7).

Las puntas de proyectil fueron la clase artefactual más representada en el sitio $(\mathrm{N}=45)$, en su mayor parte elaboradas en calcedonia y ópalo (ver Tabla 2). Solo una pequeña fracción fue confeccionada en cuarzo $(\mathrm{N}=3)$. Predominan las puntas de proyectil del subgrupo tipológico A.1. (sensu Medina et al., 2019a), con pedúnculo diferenciado, aletas entrantes y limbo triangular corto de tipo isósceles (Figura 3), con un total de 24 ejemplares. Otros subgrupos también se encuentran representados en proporciones menores, incluso puntas de proyectil apedunculadas $(\mathrm{N}=3)$. Las características generales, frecuencias absolutas y los aspectos relacionados con los sistemas de armas de los cuales formaron parte son ampliamente discutidos en Medina et al. (2019a) y Medina y Balena (2021). El resto de las clases artefactuales $(\mathrm{N}=67)$ fue elaborado mayoritariamente en forma unifacial y utilizando principalmente cuarzo, dominando los artefactos de formatización sumaria, seguidos por raspadores y perforadores. En menor frecuencia, también se identificaron raederas, muescas, cuchillos, percutores y una punta no destacada (ver Tabla 2), siendo sus características discutidas en detalle en Medina et al. (2019c).

Tabla 4. Razones referidas en el texto discriminadas por materias primas.

\begin{tabular}{|l|c|c|c|}
\hline Materia prima & $\begin{array}{c}\text { Núcleos con corteza: } \\
\text { núcleos sin corteza }\end{array}$ & $\begin{array}{c}\text { Lascas: } \\
\text { núcleos }\end{array}$ & $\begin{array}{c}\text { Lascas sin corteza: } \\
\text { lascas con corteza }\end{array}$ \\
\hline Cuarzo & 6,5 & 21,6 & 6,9 \\
\hline Andesita & 11 & 31,27 & 2,18 \\
\hline Calcedonia & 0,67 & 28,4 & 10,83 \\
\hline Ópalo & 0 & 35 & 16,5 \\
\hline Indeterminadas & 3 & 15,66 & 0,5 \\
\hline
\end{tabular}

Tabla 5. Mediana y desvío de extracciones en los núcleos discriminados por materias primas.

\begin{tabular}{|l|c|c|}
\hline \multicolumn{1}{|c|}{ Materia prima } & Mediana de extracciones & Desvío \\
\hline Cuarzo & 5 & 2.9652 \\
\hline Andesita & 5 & 1.4826 \\
\hline Calcedonia & 5,5 & 3.7065 \\
\hline Ópalo & 9 & - \\
\hline Indeterminadas & 2 & - \\
\hline
\end{tabular}


Tabla 6. Frecuencias y características generales de los desechos de talla recuperados en Boyo Paso 2 discriminados por materia prima.

\begin{tabular}{|c|c|c|c|c|c|c|}
\hline 营 & Z & 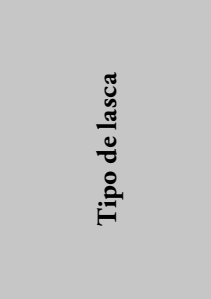 & 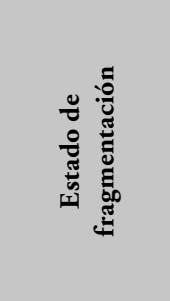 & 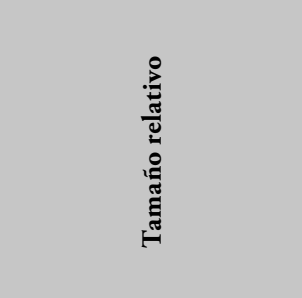 & 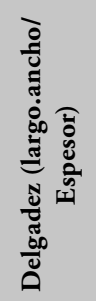 & 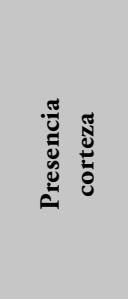 \\
\hline Cuarzo & 324 & $\begin{array}{c}\text {-Externa: } 41 \\
\text {-Interna: } 268 \\
\text {-Reactivación: } 15 \\
\text {-Adelgazamiento: } \\
0\end{array}$ & $\begin{array}{c}\text { Entera: } \\
49,07 \% \\
\text { Fragmentada: } \\
\quad 50,93 \%\end{array}$ & $\begin{array}{c}\text {-Hipermicrolasca: } 0 \% \\
\text {-Microlasca: } 2,47 \% \\
\text {-Muy pequeño: } 32,72 \% \\
\text {-Pequeño: } 27,16 \% \\
\text {-Med.-pequeńo: } 19,75 \% \\
\text {-Med.-grande: } 16,67 \% \\
\text {-Grande: } 1,23 \%\end{array}$ & 48,32 & $\begin{array}{c}- \\
\text { Presencia: } \\
\text { 12,65\% } \\
\text { Ausencia: } \\
87,35 \%\end{array}$ \\
\hline Andesita & 344 & $\begin{array}{c}\text {-Externa: } 108 \\
\text {-Interna: } 236 \\
\text {-Reactivación: } 0 \\
\text {-Adelgazamiento: } \\
0\end{array}$ & $\begin{array}{c}\text { Entera: } \\
63,66 \% \\
\text { Fragmentada: } \\
\text { 36,34\% }\end{array}$ & $\begin{array}{c}\text {-Hipermicrolasca: } 0 \% \\
\text {-Microlasca: } 0 \% \\
\text {-Muy pequeño: } 35,19 \% \\
\text {-Pequeño: } 38,43 \% \\
\text {-Med.-pequeńo: } 17,13 \% \\
\text {-Med.-grande: } 7,87 \% \\
\text {-Grande: } 1,38 \%\end{array}$ & 69,67 & $\begin{array}{c}\text { Presencia: } \\
\text { 31,40\% } \\
\text { Ausencia: } \\
\text { 68,40\% }\end{array}$ \\
\hline Calcedonia & 284 & $\begin{array}{c}\text {-Externa: } 24 \\
\text {-Interna: } 183 \\
\text {-Reactivación: } 55 \\
\text {-Adelgazamiento: } \\
22\end{array}$ & $\begin{array}{l}\text { Entera: } \\
72,89 \% \\
\text { Fragmentada: } \\
\quad 27,11 \%\end{array}$ & $\begin{array}{c}\text {-Hipermicrolasca: } 6,32 \% \\
\text {-Microlasca: } 16,84 \% \\
\text {-Muy pequeño: } 49,47 \% \\
\text {-Pequeño: } 21,58 \% \\
\text {-Med.-pequeño: } 4,74 \% \\
\text {-Med.-grande: } 1,05 \% \\
\text {-Grande: } 0 \%\end{array}$ & 60,07 & $\begin{array}{l}\text { Presencia: } \\
8,45 \% \\
\text { Ausencia: } \\
91,55 \%\end{array}$ \\
\hline Ópalo & 35 & $\begin{array}{c}\text {-Externa: } 2 \\
\text {-Interna: } 16 \\
\text {-Reactivación: } 13 \\
\text {-Adelgazamiento: } \\
4\end{array}$ & $\begin{array}{l}\text { Entera: } \\
\quad 85,71 \% \\
\text { Fragmentada: } \\
\quad 14,29 \%\end{array}$ & $\begin{array}{c}\text {-Hipermicrolasca: } 15,38 \% \\
\text {-Microlasca: } 57,69 \% \\
\text {-Muy pequeño: } 26,93 \% \\
\text {-Pequeño: } 0 \% \\
\text {-Med.-pequeño: } 0 \% \\
\text {-Med.-grande: } 0 \% \\
\text {-Grande: } 0 \%\end{array}$ & 31,7 & $\begin{array}{l}\text { Presencia: } \\
5,71 \% \\
\text { Ausencia: } \\
94,29 \%\end{array}$ \\
\hline $\begin{array}{l}\text { Indetermi- } \\
\text { nada }\end{array}$ & 47 & $\begin{array}{c}\text {-Externa: } 31 \\
\text {-Interna: } 16 \\
\text {-Reactivación: } 0 \\
\text {-Adelgazamiento: } \\
0\end{array}$ & $\begin{array}{l}\text { Entera: } \\
\quad 74,47 \% \\
\text { Fragmentada: } \\
\quad 25,53 \%\end{array}$ & $\begin{array}{c}\text {-Hipermicrolasca: } 0 \% \\
\text {-Microlasca: } 0 \% \\
\text {-Muy pequeño: } 6,06 \% \\
\text {-Pequeño: } 39,39 \% \\
\text {-Med.-pequeño: } 30,31 \% \\
\text {-Med.-grande: } 18,18 \% \\
\text {-Grande: } 6,06 \%\end{array}$ & 105,67 & $\begin{array}{l}\text { Presencia: } \\
65,96 \% \\
\text { Ausencia: } \\
34,04 \%\end{array}$ \\
\hline
\end{tabular}


Horticultura, movilidad y tecnología lítica: una mirada desde Boyo Paso 2 (900-700 años AP, Sierras...

Tabla 7. Frecuencias y tipo de talones discriminados por materia prima.

\begin{tabular}{|c|c|c|c|c|c|c|}
\hline \multirow{3}{*}{ Materia prima } & \multicolumn{6}{|c|}{ Tipos de talón } \\
\hline & \multicolumn{2}{|c|}{ Corticales y lisos } & \multicolumn{2}{|c|}{ Facetados } & \multicolumn{2}{|c|}{$\begin{array}{l}\text { Filiformes, diedros, } \\
\text { preparados y puntiformes }\end{array}$} \\
\hline & $\mathbf{n}$ & $\%$ & $\mathbf{n}$ & $\%$ & $\mathbf{n}$ & $\%$ \\
\hline Cuarzo & 257 & 44,62 & 3 & 3,7 & 64 & 16,97 \\
\hline Andesita & 239 & 41,49 & 8 & 9,88 & 97 & 25,73 \\
\hline Calcedonia & 40 & 6,94 & 65 & 80,25 & 179 & 47,48 \\
\hline Ópalo & 2 & 0,35 & 5 & 6,17 & 28 & 7,43 \\
\hline Indeterminada & 38 & 6,6 & 0 & 0 & 9 & 2,39 \\
\hline Total & 576 & 100 & 81 & 100 & 377 & 100 \\
\hline
\end{tabular}

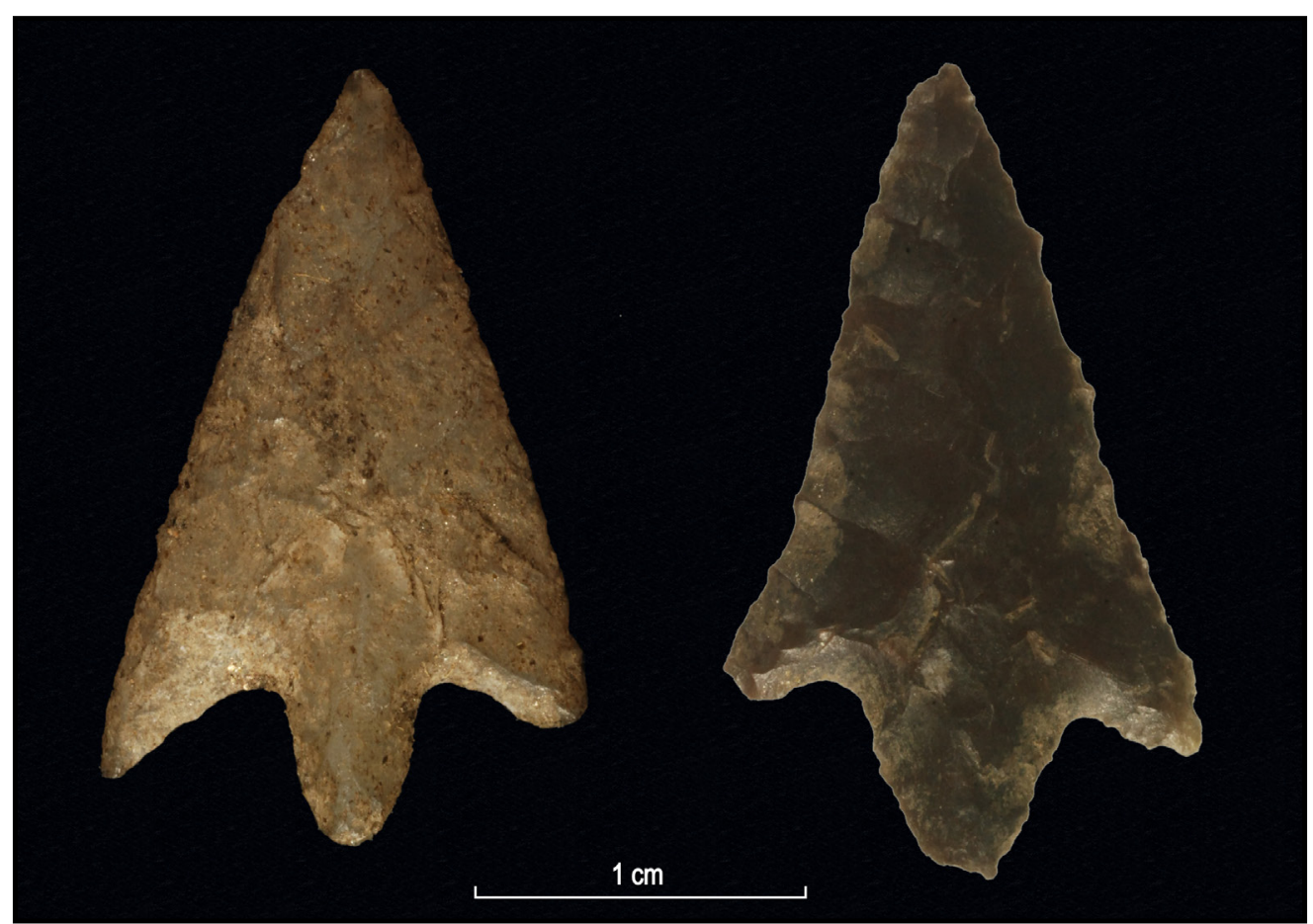

Figura 3. Ejemplos de puntas de proyectil del subgrupo tipológico A.1 (calcedonia) recuperadas en Boyo Paso 2. 


\section{Discusión}

El estudio de los núcleos y desechos de talla señaló que el conjunto de Boyo Paso 2 estuvo dominado por materias primas de regular calidad para la talla pero de amplia disponibilidad en el entorno local, como la andesita y el cuarzo, mientras que la calcedonia y el ópalo ocuparon una menor proporción. Se destaca la alta frecuencia relativa de la andesita, un material ausente o con muy baja representatividad en otros sitios de la región frente a la abrumadora presencia del cuarzo (Laguens, 1999; Pastor, 2007; Sario et al., 2017; Balena et. al., 2018, entre otros).

$\mathrm{Al}$ considerar los distintos índices y razones, los resultados indicaron que los núcleos de andesita y cuarzo rara vez mostraron signos de agotamiento y/o de explotación intensiva. Por el contrario, la información sugiere que los núcleos, una vez obtenidas las formas base necesarias, especialmente lascas espesas, eran descartados. Comportamientos similares comúnmente se asocian en la literatura arqueológica a los bajos costos de obtención de las materias primas en las cercanías del sitio (Parry y Kelly, 1987; Andrefsky, 1998). En este sentido, el cuarzo es un mineral de distribución ubicua en las Sierras de Córdoba (Petersen y Leanza, 1979; Angelelli et al., 1983; Heider et al., 2015), y el material mayormente representado en el registro arqueológico regional (Berberián, 1984; Laguens, 1999; Pastor, 2007; Rivero, 2009; Sario et al., 2017; Balena et al., 2018, entre otros). En lo que hace específicamente a la andesita, es una roca relativamente común en las proximidades del sitio (Arnosio et al., 2014), por lo que todo parece indicar que, como el cuarzo, fue explotada de manera directa a partir de depósitos primarios o secundarios durante la realización de otras actividades de subsistencia. Sin embargo, la explotación poco intensiva de la andesita y el cuarzo no puede ser explicada exclusivamente por su alta disponibilidad. También es necesario considerar otras variables no menos importantes en el marco de una economía mixta que incluía un alto grado de movilidad estacional, entre ellas la duración de la ocupación, la diversificación de las actividades de subsistencia o la planificación de un retorno al sitio, este último un comportamiento observado entre agricultores que hacen uso diversificado del paisaje a lo largo del ciclo productivo (Graham, 1994; Hill et al., 2008).

Respecto a la primera variable, la ocupación prolongada de un asentamiento está claro que conduce a un mayor uso de los materiales abundantes localmente, ya que hay menos oportunidades para obtener rocas de fuentes distantes (Parry y Kelly, 1987). En consecuencia, se espera que las proporciones de artefactos manufacturados en materiales locales sean mayores en comparación con los elaborados de materias primas no locales, mientras que estas últimas serán trabajadas más intensamente. Si bien la propuesta de Parry y Kelly (1987) dio un paso adelante para explicar los conjuntos líticos asociados a contextos de baja movilidad residencial, los arqueólogos continúan teniendo dificultades para diferenciar una ocupación residencial de tipo estacional, de seis, siete meses de duración, de una ocupación plenamente sedentaria (Rocek, 2013; Capriles, 2014; Medina et al., 2020). Esto reduce el alcance de las interpretaciones de Parry y Kelly (1987), sobre todo cuando las estrategias tecnológicas adoptadas por grupos que se encuentran en una situación intermedia entre caza-recolección móvil y una agricultura sedentaria no fueron lo suficientemente tratadas en los estudios líticos (Holdaway et al., 2010). En segundo lugar, la incorporación de cultivos en una economía de tipo mixta multiplicó los ámbitos que requerían elaborar artefactos, que muchas veces se manufacturaban con materias primas específicas y/o no-locales, como son las puntas de proyectil para la caza o defensa, hachas y azuelas para abrir espacios en el bosque serrano, recipientes cerámicos para transportar, almacenar y cocinar frutos y semillas, etcétera. De tal manera, la posibilidad de resolver problemas tecnológicos vinculados a las actividades domésticas inmediatas, a partir 
de la elaboración de artefactos expeditivos utilizando rocas abundantes y accesibles desde el sitio, desalentó invertir un mayor tiempo en la reducción y preparación de núcleos, más aún cuando las formas base obtenidas resultaron efectivas para elaborar los artefactos requeridos (Parry y Kelly, 1987; Torrence, 1989; Andrefsky, 1998). En forma no excluyente, el descarte de núcleos semipreparados también pudo responder a la previsión de un retorno al sitio (sensu Graham, 1994). En este sentido, el registro en planta de estos materiales junto con instrumentos que todavía conservaban cierta vida útil y/o no estaban agotados, como percutores, puntas de proyectil, artefactos y preformas de artefactos de hueso, conanas, manos y vasijas, podría interpretarse como una estrategia de equipamiento de lugares (Kuhn, 1995), litificando el paisaje y mejorando las condiciones para futuras ocupaciones, aspecto que cobra sentido en el marco de un sedentarismo intermitente estrechamente relacionado con la necesidad estacional de tierras para el cultivo (Medina et al., 2016). Procesos similares son utilizados en la literatura arqueológica como ejemplos de construcción de nicho y de herencia de los entornos construidos (Odling-Smee et al., 2003), dentro de los cuales este caso puede englobarse.

Aun cuando el componente tecnológico de los grupos tardíos se asentó en la expeditividad, los núcleos de calcedonia y ópalo evidenciaron un alto grado de agotamiento e incluso el aprovechamiento intensivo a partir del uso de la talla bipolar, compensando así sus costos de abastecimiento (sensu Flegenheimer et al., 1995). Este comportamiento tecnológico conservado permitió a los habitantes de Boyo Paso 2 enfrentar situaciones de escasez en el aprovisionamiento de materias primas de buena calidad para la talla, pero indispensables para la elaboración de artefactos de los cuales dependía gran parte de su subsistencia anual, como son las puntas de proyectil, la clase artefactual más representada en el sitio (Medina et al., 2019a, 2019c). La casi ausencia de desechos de talla en calcedonia y ópalo con tamańos adecuados para el soporte de pequeñas puntas de proyectil, sumado a valores altos de subproductos asociados con su manufactura, argumentan a favor de este aserto (Railey, 2010, p. 267).

En este sentido, el estudio de los núcleos y desechos de Boyo Paso 2, complementado con la información disponible sobre los conjuntos artefactuales, señala que durante la ocupación tardía del sitio coexistieron estrategias tecnológicas conservadas y expeditivas (sensu Nelson, 1991). Por un lado, se describieron estrategias tendientes a la conservación y maximización de ciertos tipos de materias primas de mejor calidad para la talla, como la calcedonia y el ópalo. Estas rocas fueron utilizadas casi exclusivamente para formatizar pequeñas puntas de proyectil triangulares con pedúnculo y aletas, incluso en mayor número que en sitios de períodos anteriores, indicando que la captura de vertebrados con arco y flecha no era una simple actividad complementaria al cultivo y la recolección. En otras rocas de menor calidad, pero más abundantes, se minimizó la inversión de esfuerzo en la reducción y producción de formas base con las cuales elaborar artefactos de corte y/o raspado a un bajo costo, que eran descartadas inmediatamente después de finalizadas las tareas para las cuales fueron utilizadas (Medina et al., 2019c).

Las características del conjunto lítico de Boyo Paso 2 también señaló semejanzas con otros sitios de la región datados para el mismo período y que se integran dentro de los circuitos de movilidad de las sociedades tardías (Pastor, 2007; Sario et al., 2017; Balena et al., 2018). Sin embargo, Boyo Paso 2 presentó ciertas particularidades, como una alta representación de la andesita y una menor proporción del cuarzo -este último absolutamente dominante en todos los sitios de la región-, revelando un potencial de información que permite un mejor acercamiento a la variabilidad de las decisiones humanas en cuanto a las estrategias tecnológicas adoptadas en un contexto de movilidad estacional que combinaba caza-recolección, horticultura y uso flexible del espacio. 


\section{Conclusión}

La tecnología lítica del Período Prehispánico Tardío de las Sierras de Córdoba ha sido caracterizada a lo largo de los años como expeditiva (sensu Nelson, 1991), dominada por artefactos con bajo grado de formatización y corta vida útil, que se elaboraban de acuerdo con las necesidades inmediatas y se descartaban luego de finalizadas las tareas (Pastor, 2007; Balena et al., 2018). Sin embargo, estas interpretaciones comienzan a resultar insuficientes para explicar la flexibilidad y el amplio rango de respuestas tecnológicas observadas en el registro arqueológico, sobre todo en el marco de una economía mixta que combinaba cultivos, caza-recolección y patrones de movilidad semisedentarios. La evidencia actualmente disponible sostiene que los grupos tardíos también explotaron en forma intensiva y conservada rocas de grano fino que requirieron mayores esfuerzos de aprovisionamiento, principalmente para desarrollar puntas de proyectil de diseño estandarizado y mayor grado de formatización, que una vez enmangados en astiles de flechas fueron fundamentales para adecuar las técnicas de caza en función de las variaciones estacionales en el tamaño de los grupos (Medina et al., 2019a). Una situación similar fue recientemente argumentada para las hachas y/o azuelas de piedra pulida (Medina et al., 2019d), una innovación propia de fines del Holoceno estrechamente vinculada a la necesidad estacional de tierras para el cultivo y una mayor recurrencia en la estructura de la movilidad. Así, la aplicabilidad de los conceptos de diseño a conjuntos instrumentales generados por poblaciones en una situación intermedia entre una caza-recolección móvil y una agricultura sedentaria constituye un problema que amerita un análisis tecnológico más profundo, atendiendo principalmente a determinar cómo su interacción se ajustaba a las necesidades de cada grupo en circunstancias particulares, incluso en términos comparativos con casos arqueológicos donde se argumente, por ejemplo, un alto grado de sedentarismo (Escola, 2004; Holdaway et al., 2010).

Una de las principales conclusiones que surgen al analizar la diversidad tecno morfológica del conjunto lítico de Boyo Paso 2 es la variedad de estrategias utilizadas en el proceso de reducción y producción de formas base con las cuales luego se elaboraron artefactos. Esto denota, como mínimo, la flexibilidad tecnológica desarrollada durante el Período Prehispánico Tardío para enfrentar el estrés de un modo de vida estacionalmente móvil y minimizar la falla en la captura de las presas de las cuales dependían. En tal sentido, se espera que la información pueda ser utilizada como modelo para interpretar la organización tecnológica durante la transición hacia la producción de alimentos en otras poblaciones del Viejo y Nuevo Mundo, en donde la incorporación de cultivos no necesariamente dio lugar a un modo de vida agrícolasedentario, sino a múltiples combinaciones entre caza-recolección, agricultura y movilidad residencial (Hard y Merrill, 1992; Kelly, 1992; Diehl, 1997; Arnold, 1999; Chaparro, 2001; Smith, 2001; Chilton, 2002; Symons, 2003; Escola, 2004; Denham et al., 2007; Hill et al., 2008; Asouti y Fairbain, 2010; López Campeny, 2010; Freeman, 2012; Bulbeck, 2013; Pérez et al., 2013; Rocek, 2013; Silva y Frank, 2013; Capriles, 2014; Hocsman, 2014; Popov et al., 2014; Gates-St Pierre, 2015; Lucero et al., 2016; Boyd, 2018; Politis y Bonomo, 2018; Ricci et al., 2018; Borgo, 2020), pero que actualmente no son visibilizadas adecuadamente por la rigidez de la concepción normativa del cambio evolutivo (Layton et al., 1991; Smith, 2001; Rocek, 2013; Grillo, 2014; Medina et al., 2020). Los datos obtenidos, de esta manera, apuntan hacia la existencia de un cierto componente tecnológico conservado entre los grupos tardíos, que, junto con la expeditividad, regían la organización de la tecnología. El aprovechamiento intensivo de aquellas rocas de mejor calidad para la talla y menos abundantes en el paisaje, en un contexto dominado por estrategias tecnológicas expeditivas, da particular relevancia a los 
resultados aquí obtenidos, en especial para comprender la amplitud de respuestas tecnológicas en casos en los que la adopción de cultivos no necesariamente derivó en una agricultura sedentaria, un patrón observado etnográficamente pero difícil de delimitar desde la cultura material.

\section{Agradecimientos}

Este trabajo es el resultado de investigaciones financiadas por la Agencia Nacional de Promoción Científica y Tecnológica (PICT-2016-201-0677). Deseamos expresar nuestro agradecimiento a D. Gobbo, I. Mlakar, J. B. Belardi, L. López, M. Cardillo, G. Chaparro, J. P. Carbonelli, F. Restifo y dos evaluadores anónimos, quienes aportaron bibliografía y comentarios que ayudaron a mejorar la calidad del manuscrito.

\section{Referencias citadas}

Andrefsky, W. (1998). Lithics. Macroscopic approaches to analysis. Cambridge: Cambridge University Press.

Aparicio, F. (1939). La Antigua Provincia de los Comechingones. En Academia Nacional de la Historia (Ed.). Historia de la Nación Argentina I, Tiempos Prehistóricos y Protohistóricos (pp. 359-386). Buenos Aires: Editorial El Ateneo.

Argüello de Dorsch, E. (1983). Investigaciones arqueológicas en el Departamento de Punilla (Provincia de Córdoba-Rep. Argentina). Sitio C.Pun.39. Comechingonia, 1, 41-60.

Arnold, P. (1999). Tecomates, residential mobility and Early Formative occupation in Coastal Lowland Mesoamérica. En Skibo J., y Feinman, G. (Eds.). Pottery and people. a dynamic interaction (pp. 159-170). Salt Lake City, UT: The University of Utah Press.

Arnosio, M., Popridkin, C., Báez, W. y Bustos, E. (2014). El volcanismo terciario: Complejo Volcánico Pocho. En Martino, R. y Guereschi, A. (Eds.). Geología y Recursos Naturales de la Provincia de Córdoba (pp. 623-647). Relatorio del XIX Congreso Geológico Argentino. Córdoba, Argentina: Asociación Geológica Argentina.

Aschero, C. (1983). Ensayo para una clasificación morfológica de artefactos líticos. Apéndices A y B (Apunte inédito para la cátedra de Ergología y Tecnología). Cátedra de Ergología y Tecnología, Facultad de Filosofía y Letras, Universidad de Buenos Aires, Buenos Aires.

Aschero, C. y Hocsman, S. (2004). Revisando cuestiones tipológicas en torno a la clasificación de artefactos bifaciales. En Ramos, M., Acosta, A. y Loponte, D. (Eds.). Temas de arqueología. Análisis lítico (pp. 7-25). Luján: Universidad Nacional de Luján, Argentina.

Asouti, E., Fairbairn, A. (2010). Farmers, gatherers or horticulturalist? Reconstructing landscapes of practice in the Early Neolithic. En Finlayson, B. y Warren, G. (Eds.). Landscapes in transition (pp. 161-172). Oxford: Oxbow Books.

Balena, I. (2020). Estrategias tecnológicas en grupos con economías mixtas: una aproximación desde el conjunto lítico de Boyo Paso 2 (Pocho, Sierras de Córdoba, Argentina). Tesis de grado. Facultad de Filosofía y Letras, Universidad de Buenos Aires, Buenos Aires, Argentina.

Balena, I., Heider, G. y Medina, M. (2018). Tecnología lítica entre las sociedades del Período Prehispánico Tardío (Sierras de Córdoba, Argentina). Mundo de Antes, 12(2), 81-105. 
Berberián, E. (1984). Potrero de Garay: Una entidad sociocultural tardía de la región serrana de la Provincia de Córdoba (Rep. Argentina). Comechingonia, 4, 71-138.

Borgo, M. (2020). La tecnología lítica del sitio Alero Dupuy (cuenca superior del Río Quinto, provincia de San Luis), Avances en la caracterización de las estrategias tecnológicas del Holoceno medio y tardío. Mundo de Antes, 14(1), 52-76.

Boyd, B. (2018). Settled? Recent debates in the archaeology of the Epipaleolithic and Pre-Pottery Neolithic of Southwest Asia. Asian Archaeology, 1, 63-73.

Bulbeck, D. (2013). The transition from foraging to farming in prehistory and 'ethnography'. World Archaeology, 45(4), 557-573.

Capriles, J. (2014). Mobile communities and pastoralist landscapes during the Formative Period in the Central Altiplano of Bolivia. Latin American Antiquity, 25(1), 3-26.

Cardillo, M., Alberti, J. y Carranza, E. (2017). Tecnología, uso de materias primas y redundancia ocupacional: la localidad Punta Odriozola, costa de la provincia de Río Negro, Argentina. Mundo de Antes, 11, 71-98.

Chaparro, G. (2001). La organización de la tecnología lítica en sociedades pastoriles prehistóricas (desde ca. 2000AP) en la quebrada de Inca Cueva: el caso de la cueva 5 (Jujuy, Argentina). Arqueología, 11, 9-47.

Chilton, E. (2002). “Towns they have none”: Diverse subsistence and settlement strategies in native New England. En Hart, J. y Rieth, R. (Eds.). Northeast subsistence-settlement change: A.D. 700-1300 (pp. 289-300). Albany, NY: The University of New York, Nueva York.

Clarkson, C. (2008). Changing reduction intensity, settlement, and subsistence in Wardaman Country, Northern Australia. En Andrefsky, W. (Ed.). Lithic Technology (pp. 286-316). Cambridge: Cambridge University Press.

Denham, T., Iriarte, J. y Vrydaghs, L. (Comp.). (2007). Rethinking Agriculture. Archaeological and Ethnoarchaeological Perspectives. Walnut Creek, CA: Left Coast Press.

Dibble, H., Schurmans, U., Iovita, R. y McLauglin, M. (2005). The measurement and interpretation of cortex in lithic assemblages. American Antiquity, 70, 545-60.

Diehl, M. (1997). Changes in architecture and land use strategies in the American Southwest: Upland Mogollon Pithouse Dwellers. A.C. 200-1000. Journal of Field Archaeology, 24, 179-194

Escola, P. (2004). La expeditividad y el registro arqueológico. Chungara. Revista de Antropología Chilena, $36,49-60$.

Flegenheimer, N., Bayón, C. y González de Bonaveri, M. (1995). Técnica simple, comportamientos complejos: la talla bipolar en la arqueología bonaerense. Relaciones de la Sociedad Argentina de Antropología, 20, 81-110.

Freeman, J. (2012). Alternative adaptive regimes for foraging and farming activities. Journal of Archaeological Sciences, 39, 3008-3017.

Gates St-Pierre, C. (2015). Horticulture on the edge: the northernmost evidence for plant cultivation in pre-contact Northeastern North America. Revista de Antropología del Museo de Entre Rios, 1(1), 21-31. 
Giorgis, M., Cingolani, A., Chiarini, F., Chiapella, J., Barboza. G., Ariza, L., Morero, L., Gurvich, D., Tecco, P., Subilis, R., Cabido, M. (2011). Composición florística del Bosque Chaqueño Serrano de la provincia de Córdoba, Argentina. Kurtziana, 36, 9-43.

González, A. (1943). Arqueología del Yacimiento Indígena de Villa Rumipal (Pcia. de Córdoba). Publicaciones del Instituto de Arqueología, Lingüistica y Folklore (IV). Córdoba: Universidad Nacional de Córdoba.

Graham, M. (1994). Mobile farmers. An ethnoarchaeological approach to settlement organization among the Rarámuri of Northwestern Mexico. Michigan: Internacional Monographs in Prehistory.

Grillo, K. (2014). Pastoralism and Pottery Use: An Ethnoarchaeological Study in Samburu, Kenya. African Archaeological Review, 31(2), 105-130.

Hard, R., Merrill, W. (1992). Mobile agriculturalist and the emergence of sedentism: perspectives from Northern Mexico. American Anthropologist, 94, 601-620

Heider, G., Ortiz Suarez, A., Rivero, D., Baldo, E., Pastor, S., Ramos, G., Borgo, M, Gil, R., Chiesa, J., Costa, C., Recalde, A., Curtoni, R., Capriolo, J., y Muñoz, L. (2020). Estudios geoarqueológicos de fuentes y canteras líticas de las Sierras Pampeanas y llanuras adyacentes. Revista del Museo de Antropología, 13(1), 31-36.

Heider G., Rivero, D., y Baldo, E. (2015). Rocas de uso arqueológico en Sierras Centrales. Fuentes de recursos líticos identificadas y potenciales en las provincias de Córdoba y San Luis, Argentina. Revista de Antropología del Museo de Entre Ríos, 1(2), 55-72.

Hill, M., Bruder, S., Beck, M., Phillips, B. (2008). Mobile horticulturalist in the Western Papaguería. Kiva, 74, 33-69.

Hocsman, J. (2014). Continuities and discontinuities in the process of transition to food production in Antofagasta de la Sierra (Southern Puna of Argentina): the case of flaked stone tools. En Pintar, E. (Ed.). Hunter-gatherers from a high-elevation desert: people of the Salt Puna (pp. 201-230). Oxford: BAR International Series 2641.

Holdaway, S., Wendrich, W. y Phillipps, R. (2010). Identifying low-level food producers: detecting mobility from lithics. Antiquity, 84, 185-194.

Kelly, R. (1992). Mobility/sedentism: concepts, archaeological measures, and effects. Annual Review in Anthropology, 21, 43-6.

Kuhn, S. (1995). Mousterian Lithic Technology. An Ecological Perspective. Princeton, NJ: Princeton University Press.

Laguens, A. (1999). Arqueología del Contacto Hispano-Indigena. Un Estudio de Cambios y Continuidades en las Sierras Centrales de Argentina. Oxford: BAR International Series 801.

Laguens, A., Bonnín, M. (2009). Sociedades Indigenas de las Sierras Centrales. Arqueología de Córdoba y San Luis. Córdoba: Editorial de la Universidad Nacional de Córdoba.

Layton, R., Foley, R., y Williams, E. (1991). The transition between hunting and gathering and the specialized husbandry of resources. Current Anthropology, 32, 255-274. 
López, L. (2018). Archaeobotany in central Argentina: macro- and microscopic remains at several archaeological sites from early Late Holocene to early colonial times (3,000-250 BP). Vegetation History and Archaeobotany, 27, 219-228.

López Campeny, S. (2010). De un hogar en la Puna... Relatos de idas y vueltas. En Albeck, E., Scattolin, M. y Korstanje, M. (Eds.). El Hábitat Prehispánico. Arqueología de la Arquitectura y de la Construcción del Espacio Organizado (pp. 215-242). San Salvador de Jujuy: EDIUNJU.

Lucero, G., Castro, S. y Cortegoso V. (2016). Tecnología lítica de cazadores y pastores andinos: cambios y continuidades en la explotación de recursos líticos durante el Holoceno en el NO de San Juan. Revista del Museo de Antropología, Suplemento Especial, 1, 65-74.

Medina, M. y Balena, I. (2021). Tiny Arrowpoints, Bone-tipped Projectiles and Foraging During the Late Prehispanic Period (Sierras of Córdoba, Argentina). En Belardi, J., Bozzuto, D, Fernández, P., Moreno, E. y Neme, G. (Eds.). Ancient Hunting Strategies in Southern South America (pp. 33-58). The Latin American Studies Book Series, Springer, NY.

Medina, M., Balena, I. y Moulia, B. (2019c). Tecnología lítica durante el Período Prehispánico Tardío: una aproximación desde el sitio Boyo Paso 2 (Sierras de Córdoba, Argentina). En Laguens, A., Bonnin, M., Marconetto, B. y Costa, T. (Eds.). Libro de resúmenes XX Congreso Nacional de Arqueología Argentina (pp. 23-26). Córdoba: Universidad Nacional de Córdoba, Argentina.

Medina, M., Balena, I. y Rivero, D. (2019a). Proyectiles y procesos de intensificación: una aproximación desde Boyo Paso 2, 1500-750 AP (Sierras de Córdoba, Argentina). Chungara. Revista de Antropología Chilena, 51(4), 517-529.

Medina, M., Balena, I., Vázquez, E., Coriale, N. y Pastor, S. (2019d). Bosques, Claros y Cultivos: Una Aproximación Tecnológico-funcional a las Hachas y/o Azuelas Líticas de las Sierras de Córdoba (Argentina). Latin American Antiquity, 30(1), 142-157.

Medina, M., Campos, M., Ávila, M., Soibelzon, E., Fernández, F, (2019b). Animal food during the Sierras of Córdoba Late Prehispanic Period (Argentina). A zooarchaeological view from Boyo Paso 2. Anthropozoologica, 54(10), 83-95.

Medina, E., López, L., Buc, N. (2018). Bone tool and tuber processing: a multi-proxy approach at Boyo Paso 2, Argentina. Antiquity, 92, 1040-1055.

Medina, M., López, L., Campos, M., Saur Palmieri, V., y Pastor, S. (2020). Pit-houses, Seasonality and Subsistence Resources: An Essay from Boyo Paso 2 (ca. 900-700 BP, Sierras of Córdoba, Argentina). Archaeological and Anthropological Sciences, 12, 119. http://dx.doi.org/10.1007/s12520-020-01066-6.

Medina, M., Pastor, S., Apolinaire, E., Turnes, L. (2011). Late Holocene subsistence and social integration in Sierras of Córdoba (Argentina): the south-american ostrich eggshells evidence. Journal of Archaeological Science, 38, 2071-2078

Medina, M., Pastor, S., y Berberián, E. (2014). “Es gente fazil de moverse de una parte a otra”. Diversidad en las estrategias de subsistencia y movilidad prehispánicas tardías (Sierras de Córdoba, Argentina). Complutum, 25(1), 73-88.

Medina, M., Pastor, S., y Recalde, A. (2016). The archaeological landscape of late prehispanic mixed foraging and cultivation economy (Sierras of Córdoba, Argentina). Journal of Anthropological Archaeology, 
$42,88-104$.

Nelson, M. (1991). The study of technological organization. Archaeological Method and Theory, 3, 57-100.

Odling-Smee, F., Laland, K. y Feldman, M. (2003). Niche construction: the neglected process in evolution. Princeton, NY: Princeton University Press.

Parry, W. y Kelly, R. (1987). Expedient core technology and sedentism. En Johnson, K., y Morrow, C. (Eds.). The Organization of Core Technology (pp. 285-312). Boulder, CO: Westview Press.

Pastor, S. (2007). Arroyo Tala Cañada 1 (Valle de Salsacate). Espacio doméstico y productivo en el sector central de las Sierras de Córdoba (Argentina) durante el Período Prehispánico Tardío (1000-300 AP). Arqueología, 14, 41-74.

Pastor, S., Medina, M., Recalde, A., López, L. y Berberián, E. (2012). Arqueología de la región montañosa central de Argentina. Avances en el conocimiento de la historia prehispánica tardía. Relaciones de la Sociedad Argentina de Antropología, 37, 89-112.

Paulides, L. (2006). El núcleo de la cuestión. El análisis de los núcleos en los conjuntos líticos. En Pérez de Micou, M. (Ed.). El modo de hacer las cosas. Artefactos y ecofactos en arqueología (pp. 67-101). Buenos Aires: Universidad de Buenos Aires.

Pérez, A., Reyes, V. y Erra, G. (2013). Economías mixtas de la Patagonia Noroccidental Argentina y Centro Sur de Chile. En Nicoletti, M. y Núñez, P. (Eds.). Araucania-Norpatagonia: la territorialidad en debate. Perspectivas ambientales, culturales, sociales, politicas y económicas (pp. 119-136). Bariloche: Universidad Nacional de Río Negro.

Politis, G. y Bonomo, M. (2018). Estado actual y perspectivas de Goya-Malabrigo, una sociedad indígena del Noreste Argentino. En Politis, G. y Bonomo, M (Eds.). Goya-Malabrigo. Arqueología de una Sociedad Indigena del Noreste Argentino (pp. 9-44). Tandil: Editorial UNICEN.

Popov, A., Tabarev, A., y Mikishin, Y. (2014). Neolithization and ancient landscapes in southern Primorye, Russian Far East. Journal of World Prehistory, 27, 247-261.

Railey, J. (2010). Reduced Mobility or the Bow and Arrow? Another Look to 'Expedient' Technologies and Sedentism. American Antiquity, 75(2), 259-286.

Recalde, A. y López, L. (2017). Las sociedades prehispánicas tardías en la región septentrional del centro de Argentina (Sierras del Norte, Córdoba). Avances a su conocimiento desde los recursos vegetales. Chungara. Revista de Antropología Chilena, 49(4), 573-588.

Reimer, P., Bard, E., Bayliss, A., Beck, W., Blackwell, P., Bronk Ramsey, C., Buck, C., Cheng, H., Edwards, L., Friedrich, M., Grootes, P., Guilderson, T., Haflidason, H., Hajdas, I., Hatté, C., Heaton, T., Hoffmann, D., Hogg, A., Hughen, K., Kaiser, F., Kromer, B., Manning, S., Niu, M., Reimer, R., Richards, D., Scott, M., Southon, J., Staff, R., Turney, C., Van Der Plicht, J. (2013). INTCAL13 and MARINE13 radiocarbon age calibration curves 0e50,000 years cal BP. Radiocarbon, 55, 1859-1887.

Ricci, A., D’Anna, M., Lawrence, D., Helwing, B., y Aliyev, T. (2018). Human mobility and early sedentism: the Late Neolithic landscape of southern Azerbaijan. Antiquity, 92, 1445-1461.

Rivero, D. (2009). Ecología de Cazadores-Recolectores del Sector Central de las Sierras de Córdoba (Rep. Argentina). Oxford: BAR International Series 2007. 
Rocek. T. (2013). The Dunlap-Salazar site (La 51344) and the context of village origins in the Jornada Highlands. En Van Pool, C. y McCarthy, E. (Eds.). Papers from the 17th Biennal Jornada Mogollon Conference in 2011 (pp. 137-150). El Paso, TX: El Paso Museum of Archaeology.

Sario, G. (2013). Sources of lithic material procurement in Estancia La Suiza archeological locality (San Luis, Argentina). Archaeological and Anthropological Science, 5, 245-254.

Sario, G., Pautassi, E. y Salvatore, M. (2017). Canteras-taller El Ranchito (Dpto. Ischilín, Córdoba). Una primera aproximación en la caracterización de fuentes y al análisis de los conjuntos líticos. Revista del Museo de Antropología, Suplemento especial, 1, 59-64.

Serrano, A. (1945). Los Comechingones. Serie Aborígenes Argentinos I. Córdoba: Instituto de Arqueología, Lingüística y Folklore de la Universidad Nacional de Córdoba.

Silva, F., y Frank, R. (2013). Deconstructing the Neolithic myth: the implications of continuity for European Late Prehistory. Anthropological Notebooks, 19, 223-235.

Smith, B. (2001). Low-Level food production. Journal of Archaeological Research, 9, 1-43.

Symons, J. (2003). Obsidian artefacts and land-use in the mid-Holocene of the Willaumez Peninsula, Papua New Guinea. Australian Archaeology, 57, 128-134.

Torrence, R. (1989). Tools as optimal solutions. En Torrence, R. (Ed.). Time, energy, and stone tools (pp. 1-6). Cambridge: Cambridge University Press. 